\title{
EVIDÊNCIAS SOBRE A SÍFILIS CONGÊNITA: UMA REVISÃO DE LITERATURA
}

\section{Anna Carolina Dockhorn de Menezes Carvalho Costa ${ }^{1}$, Ana Luiza Cotta Mourão Guimarães ${ }^{1}$, Daniel Sossai Altoé1; Paula de Souza Silva Freitas ${ }^{2}$}

${ }^{1}$ Acadêmicos de Medicina, Escola de Ciências da Santa Casa de Misericórdia de Vitória (EMESCAM), Vitória, Espírito Santo.

${ }^{2}$ Enfermeira, Mestre e Doutora em Saúde Coletiva, Departamento de Enfermagem, Universidade Federal do Espírito Santo, Vitória Espírito Santo.

DOI: 10.47094/IICNNESP.2021/79

\section{RESUMO}

A sífilis é uma doença que pode ser transmitida no ato sexual e de mãe infectada para o feto, de notificação compulsória e causada pelo Treponema pallidum. Os recém-nascidos de mães infectadas podem apresentar sinais sepse like, baixo peso além de prematuridade. Trata-se de uma revisão integrativa utilizando os descritores "Treponema pallidum” AND "Syphilis" AND "Congenital” para busca no PubMed. Após leitura de títulos e resumos foram selecionados 22 artigos para sustentar a fundamentação teórica. A sífilis congênita é uma das principais causas evitáveis de natimortos no mundo, está associada à qualidade no cuidado à saúde materna e faz parte da investigação no prénatal. Diversos são os sintomas de recém nascidos com sífilis congênita, abrangendo icterícia, rinite, alterações faciais, dentes de Hutchinson e deficiência intelectual e hepatomegalia. As altas taxas de sífilis congênita e de complicações durante a gravidez elucidam o cenário nacional de precariedade do rastreio e do tratamento.

PALAVRAS-CHAVE: Treponema pallidum. Sífilis. Congênita.

ÁREA TEMÁTICA: Outros.

\section{INTRODUÇÃO}

Sífilis é uma infecção transmissível de forma sexual (IST) e verticalmente, ou seja, de mãe para prole, causada pela espiroqueta Treponema pallidum e é de notificação compulsória no Brasil (RADOLF et al., 2016; BEZERRA et al., 2019). O risco de transmissão materno-fetal é maior na sífilis primária e secundária, seguida pela sífilis latente e terciária. Recém-nascidos $(\mathrm{RN})$ de mães infectadas são, frequentemente, pré-termo, baixo peso ao nascer ou possuem sinais clínicos que mimetizam sepse. Essa IST é a segunda principal causa evitável de natimortalidade em todo o mundo. A infecção congênita pode ser suspeitada a partir da quantificação do VDRL: se maior que 4 vezes o VDRL materno, há grandes chances de confirmação (PEELING et al., 2017). 


\section{METODOLOGIA}

Realizou-se uma revisão integrativa de literatura na base de dados PubMed, iniciada e findada em abril de 2021 utilizando-se os descritores conferidos no Medical Subjetics Headings (MeSH), “Treponema pallidum”, "Syphilis”, “Congenital”, intercalados pelo descritor booleano AND. Por tal busca foram encontrados 424 artigos, foram então selecionados artigos publicados nos últimos cinco anos, em inglês e português, texto completo e artigos que correspondem à questão norteadora: “Quais as evidências científicas sobre as características e condutas para sífilis congênita?" obtendo no final 22 artigos que foram considerados para fundamentação teórica.

\section{FUNDAMENTAÇÃO TEÓRICA}

A Sífilis Congênita (SC) é uma das principais causas de natimortos preveníveis no mundo e atua como preditor da qualidade no cuidado à saúde materna. Por este motivo, é considerado conduta padrão o rastreamento e tratamento da sífilis nas consultas pré-natais (RADOLF et al., 2016; BEZERRA et al., 2019; PEELING et al., 2017). O diagnóstico de RNs com sífilis congênita é difícil, tendo em vias que a maioria deles é assintomática. Sem o rastreamento e tratamento destes RNs, as manifestações clínicas aparecem por volta dos três meses, sendo elas listadas a seguir: hepatomegalia, icterícia, rinite, linfadenopatia generalizada, erupção cutânea, gomas de pele e mucosas, alterações faciais, curvatura anterior da canela (canela de sabre), dentes de Hutchinson e deficiência intelectual e paralisia dos nervos cranianos (HUSSAIN, VAIDYA 2021).

O tratamento do RN consiste em penicilina benzatina intravenosa de $6 / 6 \mathrm{~h}$ por $10-15$ dias OU penicilina procaína IM diariamente por 10-15 dias e a prevenção da infecção congênita consiste no diagnóstico e tratamento da mãe com penicilina G benzatina (PEELING et al., 2017). O tratamento materno é simples e seguro, sendo utilizado, também, penicilina $\mathrm{G}$ benzatina com 2,4 milhões de doses 1 vez na semana por 3 semanas (HUSSAIN, VAIDYA 2021).

\section{CONSIDERAÇÕES FINAIS}

As altas taxas de sífilis congênita e de complicações durante a gravidez revelam um cenário nacional em que a precariedade do rastreio e do tratamento se tornaram pano de fundo do que é, atualmente, um problema de saúde pública. A melhoria na qualidade do atendimento pré-natal é fator preponderante para um combate efetivo.

A ocorrência de casos de sífilis neonatal pode traduzir ou uma falha no tratamento materno (quando a penicilina é substituída por ceftriaxone ou quando a mãe não retorna para as doses necessárias) ou por reinfecção materna - para os casos em que a mãe consiste em um grupo de risco como pessoa em situação de rua ou como profissional do sexo - ou, por ineficiência profissional do trabalhador da saúde ao realizar o pré-natal da gestante ou, ainda, por negligência materna em procurar o serviço de saúde ou qualquer outra situação que impeça a gestante de fazê-lo. Neste último podemos citar violência doméstica, tráfico humano, situações psicológicas como estupro, dentre outros. 
Na questão do profissional da saúde, podemos elencar situações como falta de recursos físicos e humanos - nas instituições públicas, inexperiência causada pela mercantilização da educação médica e o próprio desinteresse humano. É necessário, portanto, instituir melhores políticas públicas para que ampare essa população - gestantes - e investimento nas áreas de unidades de saúde e serviço social.

\section{PRINCIPAIS REFERÊNCIAS}

BEZERRA, Maria; et al. Congenital Syphilis as a Measure of Maternal and Child Healthcare, Brazil. [S.l.]: Emerging Infectious Diseases, 2019.

HUSSAIN, Syed A; VAIDYA, Ruben. Congenital Syphilis. [S.l]: Treasure Island, 2021

PEELING, Rosanna W; et al. Syphilis. Nature Reviews Disease Primers. [S.l.]: Springer Science and Business Media LLC, 2017.

RADOLF, Justin; et al. Treponema pallidum, the syphilis spirochete: making a living as a stealth pathogen. [S.l.]: Nature Reviews Microbiology, 2016. 